\title{
Validity and reliability of the Foot Function Index (FFI) questionnaire Brazilian-Portuguese version
}

\author{
Bruna Reclusa Martinez ${ }^{1}$, Isabela Maschk Staboli ${ }^{1}$, Danilo Harudy Kamonseki ${ }^{1}$, Elly Budiman-Mak² \\ and Liu Chiao Yi ${ }^{1 *}$
}

\begin{abstract}
Purpose: To evaluate the validity and reliability of the Foot Function Index (FFI) in its Brazilian Portuguese version. Methods: The validity and reliability of the FFI were tested in 50 volunteers, with plantar fasciitis, metatarsalgia and chronic ankle sprain. The FFI validity process used the Short Form-36 (SF-36) and Foot and Ankle Outcome Score (FAOS) questionnaires. The correlation between FFI, SF-36 and FAOS was done using the Pearson's linear coefficient. The inter and intra-evaluator reliability was ascertained by means of the intraclass correlation coefficient (ICC) and the internal consistency by means of Cronbach's alpha coefficient. The scores were used to assess the standard error measurement (SEM), minimal detectable change (MDC) and ceiling floor and effects.

Results: The validity process showed that there were correlations between FFI and the "pain" and "social aspects" subscales of SF-36 and all subscales of FAOS, except for "other symptoms". The Brazilian-Portuguese version of FFI showed excellent intra and interevaluator correlations, with an ICC range of 0.99-0.97 and score reliability that was considered highly satisfactory, with Cronbach's alpha range of 0.80-0.61. The SEMs for inter and intra-evaluator reliability were 1.32 and 1.08, respectively. The MDC was 2.42 (90\% confidence interval). No ceiling and floor effect were detected.

Conclusions: The Brazilian-Portuguese version of the FFI questionnaire was found to be a valid and reliable instrument for foot function evaluation, and can be used both in scientific settings and in clinical practice.
\end{abstract}

Keywords: Foot diseases, Questionnaires, Outcome assessment, Validation studies

\section{Background}

Evaluating musculoskeletal disorders is essential in order to determine physical impairments among individuals. However, due to the impact caused by these disorders on the state of health and quality of life, healthcare professionals are increasingly giving emphasis to analyses from the patients' perspective. Thus, conventional evaluations such as strength and range of motion are being added through valid measurements that can determine functional, social and emotional characteristics (Eechaute

\footnotetext{
${ }^{*}$ Correspondence: liu.unifesp@gmail.com

1 Department of Human Movement Sciences, Federal University of São Paulo, Rua Silva Jardim, 136, Santos, SP CEP 11015-020, Brazil

Full list of author information is available at the end of the article
}

et al. 2007; Hale and Hertel 2005; Hunt and Hurwit 2013; Kirkley and Griffin 2003; Shultz et al. 2013).

One in every five middle-aged person presents foot and ankle pain, and this may compromise locomotion, impairment of balance and a limitation in functional activities of daily living (Thomas et al. 2011). Pathological conditions of the ankle and foot results from therapeutic interventions are under evaluation by healthcare professionals and researchers using self-reported outcome instruments. These instruments make it possible to use of reliable measurements for patients' perceptions, and specific instruments have been standardized in order to follow up and evaluate the effects of a given intervention (Martin and Irrgang 2007).

The Foot Function Index (FFI) questionnaire (Budiman-Mak et al. 1991) and other four specific instruments 
for the ankle and foot (Bennett et al.1998; Binkley et al.1999; Martin et al. 2005; Williams et al. 2003) are the only ones for these body parts that have been identified as presenting positive evidences about their usage. This can be stated because these questionnaires encompass the four categories of content validity, construct validity, reliability and responsiveness (Martin and Irrgang 2007). The FFI has also shown excellent responsiveness through presenting positive level three ratings in relation to its capacity in order to determine changes resulting from an intervention among patients with rheumatoid arthritis (van der Leeden et al. 2008). Additionally, it was classified as the fourth most used scale for orthopedic ankle and foot evaluations over a nine-year period (2002-2011) (Hunt and Hurwit 2013; Martin et al. 2014).

The FFI questionnaire was developed to measure the impact of foot pathologies on function in terms of pain, disability and activity restriction. The questionnaire is composed by 23 items distributed into three subscales: disability (5 items), activity limitation (9 items) and pain (9 items) (Budiman-Mak et al. 1991). It was developed in English (Budiman-Mak et al. 1991) and valid translated versions have been produced for use in Chinese (Wu et al. 2008), German (Naal et al. 2008), French (Pourtier-Piotte et al. 2015), Italian (Martinelli et al. 2014) and Spanish (Paez-Moguer et al. 2014). Because of the importance of standardization when using measures of evaluation, questionnaires developed in foreign languages must be translated and their psychometric properties evaluated, to create equivalence between studies. The FFI questionnaire was recently translated and culturally adapted into Brazilian Portuguese (Yi et al. 2015), and the aim of the present study was to evaluate the validation and reliability of the Brazilian version of the FFI questionnaire.

\section{Methods}

\section{Subjects}

The sample size was calculated by using the total score of the original FFI questionnaire (Budiman-Mak et al. 1991), with $95 \%$ of confidence and $90 \%$ of power and was obtained a number of 46 subjects (Sousa and Rojjanasrirat 2011). To prevent loss of volunteers, 50 patients were enrolled in this study. They were clinically diagnosed with plantar fasciitis (56 \%), metatarsalgia (14 \%) and lateral sprain of the ankle (30\%) in which the injuries occurred more than 6 months earlier. All these patients were seen at our institution's Physiotherapy Unit and Orthopedics and Traumatology Outpatient Clinic.

The inclusion criteria for the plantar fasciitis were: (1) plantar medial heel pain, most noticeable with initial steps after a period of inactivity; (2) heel pain precipitated by a recent increase in weight-bearing activity; (3) pain with palpation of the proximal insertion of the plantar fascia; (4) positive windlass test (Martin et al. 2014). The criteria for metatarsalgia were: (1) pain on metatarsals heads during palpation; (2) Mulder positive sign (Espinosa et al. 2008). The lateral ankle sprain criteria were: (1) history of at least 1 significant ankle sprain; (2) inflammatory symptoms including pain and swelling; (3) interruption of the physical activity for at least 1 day after the sprain (Gribble et al. 2014).

The volunteers included in the study were of both genders ( $76 \%$ female), with an average age of $32.9 \pm 14.13$ years (range 18-60 years) and all of them attended school until at least fully grading high school. Patients with cognitive alterations, neurological conditions and other lower-limb diseases were excluded.

\section{Testing the psychometric properties Validity}

The validity of the Brazilian version of the FFI questionnaire was tested in order to establish the correlation among the proposed instrument and instruments that had already been translated and validated (Andresen 2000). The Brazilian-Portuguese version of the Medical Outcomes Study 36-item Short Form Health Survey (SF36) (Ciconelli et al. 1999) and the Foot and Ankle Outcome Score (FAOS) (Imoto et al. 2009) questionnaires were used for the validity process. The questionnaires were applied by the same evaluator, through interviews, as the other questionnaires validity process conducted in Brazil (Ciconelli et al. 1999; Imoto et al. 2009; Yi et al. 2015). The completion time of the FFI questionnaire lasted from 5 to $10 \mathrm{~min}$.

FFI score The calculus to obtain the score for each subscale is done by using the following formula: the sum of the score from all items answered by the patient/divided by the total score possible for the subscale multiplied by 100. If the patient does not perform an activity indicated by one of the subscale items (for example, not using auxiliary devices), this item is considered to be not applicable. Thus, the scores for such items will not be considered in the total sum for the subscale (Budiman-Mak et al. 1991).

The final score of the questionnaire is calculated using the formula: sum of the final percentages of all subscales divided by three (total number of subscales). The results may vary from 0 to $100 \%$ and are directly proportional to the limb's functional impairment, such that the higher the percentage is, the greater the functional alteration presented by the patient is (Budiman-Mak et al. 1991).

Short Form Health Survey (SF-36) SF-36 is a multidimensional instrument used to evaluate quality of life. It is composed by 36 items distributed into eight scales: physical functioning, physical role functioning, bodily pain, 
general health perceptions, vitality, social role functioning, emotional role functioning and mental health. The total score from each scale varies from 0 to 100 points, where zero represents the worst state of health and 100 the best state (Ciconelli et al. 1999).

Foot and Ankle Outcome Score (FAOS) FAOS is a questionnaire that is used to evaluate symptoms and functional limitations caused by ankle and foot alterations. The questionnaire consists of 42 items distributed into five subscales: pain (9 items), symptoms (7 items), function in daily living (17 items), function in sports and recreation (5 items) and quality of life (4 items) (Imoto et al. 2009).

The score is calculated for each subscale using the following formula: 100 - (subject score multiplied by 100 divided by the maximum score possible in the subscale). Scores vary from zero to 100 , where zero indicates extreme symptoms and 100 indicates absence of symptoms (Imoto et al. 2009).

\section{Reliability}

Reliability was tested by evaluating the reproducibility (test/retest) and internal consistency (IC). Reproducibility is the extent to which the same results from the questionnaire are obtained through different administrations. Internal consistency indicates the extent to which the items in a subscale are correlated, in order to evaluate homogeneity (Andresen 2000; Eechaute et al. 2007; Kirkley and Griffin 2003).

Inter-observer reliability is measured through applying the FFI questionnaire on two occasions: initially by evaluator $\mathrm{A}$ and after a period of at least an hour, by evaluator $\mathrm{B}$, as the other validity questionnaires process conducted in Brazil (Ciconelli et al. 1999; Imoto et al. 2009; Yi et al. 2015). A third administration of the questionnaire was made in order to evaluate intra-observer reliability, performed by evaluator A after a time interval of a maximum of seven days after the first application (Terwee et al. 2007). The questions and alternatives of the FFI were read out loudly to all volunteers, without providing explanations, with the aim of not influencing the responses. During the period between administrations of the questionnaires, the volunteers were instructed to maintain their daily activities.

\section{Ceiling and floor effects}

Ceiling and floor effects of FFI were calculated. These effects are calculated in order to evaluate the entire spectrum of a condition's severity with the items it contains (Eechaute et al. 2007). The ceiling and floor effects occur when the maximum or minimum possible score is achieved by a substantial portion of the sample of participants (Eechaute et al. 2007).

\section{Ethical considerations}

This study was approved by the Research Ethics Committee, under protocol number 226.521, and all the participants signed the free and informed consent statement.

\section{Statistical analyses}

Descriptive statistical analysis on the sample was performed using means and standard deviations (SD). The total FFI score was correlated with the subscales of the SF-36 and FAOS questionnaires, by means of Pearson's linear correlation coefficient. The alpha error was set at $\mathrm{p}<0.05$.

To ascertain the intra and inter-observer reliability, the interclass correlation coefficient (ICC) was calculated. The IC of the FFI subscales was evaluated by means of Cronbach's alpha coefficient. The reliability results were combined with the total FFI scores and their subscales in order to define the standard error of measurement (SEM) (Beaton et al. 2000). The SEM was calculated using the following formula: SEM $=\operatorname{SD} 1 . \sqrt{ }(1-$ ICC $)$, where $\mathrm{SD} 1=$ is the standard deviation of the initial evaluation and ICC $=$ the ICC found in the reproducibility analysis (Beaton et al. 2000; Leggin et al. 2006; Lopes et al. 2008; Martin and Irrgang 2007).

The error associated with applying the FFI over this time interval also defined the minimal detectable change (MDC), i.e. the minimum amount of change necessary for the FFI score (with $90 \%$ confidence) to be considered to be a real change over the time frame of a maximum of one week. The MDC was calculated using the following formula: $\mathrm{MDC}=1.65 . \sqrt{ } 2 . \mathrm{SEM}$ (Leggin et al. 2006; Lopes et al. 2008; Martin and Irrgang 2007).

A ceiling and floor effects were considered if more than $15 \%$ of the respondents achieved the lowest or highest (0-100) possible score of FFI (Eechaute et al. 2007).

\section{Results \\ Validity}

Table 1 presents the scores obtained (mean, standard deviation and variation) for the FFI, SF-36 and FAOS questionnaires.

When correlating the total score from the FFI questionnaire with the subscales of the SF-36 questionnaire, a correlation between the subscales "bodily pain" $(\mathrm{r}=-0.36 ; \mathrm{p}=0.010)$ and "social role functioning" $(r=-0.36 ; p=0.011)$ was found. In relation to the FAOS questionnaire, there were correlations between the total FFI score and the subscales "pain" $(\mathrm{r}=-0.58 ; \mathrm{p}=0.001)$, "function, daily living" ( $r=-0.39 ; p=0.006)$, "function, sports and recreational activities" $(\mathrm{r}=-0.50 ; \mathrm{p}=0.001)$ and "quality of life" $(\mathrm{r}=-0.37 ; \mathrm{p}=0.009)$ (Table 2). Only the subscale "other symptoms" $(\mathrm{r}=-0.19 ; \mathrm{p}=0.187)$ showed no correlation with the FFI questionnaire. 
Table 1 FFI, FAOS and SF-36 questionnaires scores

\begin{tabular}{lcr}
\hline Questionnaires $\mathbf{n}=\mathbf{5 0}$ & Mean (SD) & Variation \\
\hline FFI Total (0-100) & $20.54(15.17)$ & $0-59.0$ \\
Disability & $12.34(12.91)$ & $0-48.1$ \\
Activity limitation & $18.89(14.22)$ & $0-58.0$ \\
Pain & $30.39(24.94)$ & $0-96.8$ \\
FAOS (0-100) & & \\
Pain & $75.11(15.29)$ & $38.8-97.2$ \\
Other symptoms & $73.86(12.53)$ & $35.7-100$ \\
Function, daily living & $87.68(11.38)$ & $57.3-100$ \\
Function, sports and recreational activities & $68.50(18.82)$ & $25.0-100$ \\
Quality of life & $45.75(21.48)$ & $6.25-81.2$ \\
SF-36 (0-100) & & \\
Physical functioning & $80.40(18.32)$ & $30.0-100$ \\
Physical role functioning & $64.00(35.05)$ & $0-100$ \\
Bodily pain & $49.54(21.73)$ & $0-100$ \\
General health perceptions & $61.62(23.19)$ & $22.0-100$ \\
Vitality & $56.50(20.31)$ & $5.0-90.0$ \\
Social role functioning & $78.25(20.33)$ & $25.0-100$ \\
Emotional role functioning & $53.33(40.19)$ & $0-100$ \\
Mental health & $66.48(20.25)$ & $20.0-100$ \\
\hline FFF Foot Function Index, FAOS Foot and Ann & & \\
& &
\end{tabular}

FFI Foot Function Index, FAOS Foot and Ankle Outcome Score, SF-36 Short-Form $36, n$ volunteer number, $S D$ standard deviation

Table 2 Correlation among FFI total score and SF-36-FAOS questionnaires subscales

\begin{tabular}{lll}
\hline $\mathbf{n}=\mathbf{5 0}$ & $\begin{array}{l}\text { Correlation } \\
\text { coefficient }(\mathbf{r})\end{array}$ & $\boldsymbol{p}$ value \\
\hline SF-36 & -0.24 & \\
$\quad$ Physical functioning & -0.11 & 0.090 \\
Physical role functioning & -0.36 & 0.465 \\
Bodily pain & -0.15 & $0.010^{*}$ \\
General health perceptions & -0.16 & 0.283 \\
Vitality & -0.36 & 0.276 \\
Social role functioning & -0.28 & $0.011^{*}$ \\
Emotional role functioning & -0.22 & 0.052 \\
Mental health & & 0.131 \\
FAOS & -0.58 & \\
Pain & -0.19 & $0.001^{* *}$ \\
Other symptoms & -0.39 & 0.187 \\
Function, daily living & -0.50 & $0.006^{*}$ \\
Function, sports and recreational & & $0.001^{* *}$ \\
activities & -0.37 & $0.009^{*}$ \\
\hline
\end{tabular}

FFI Foot Function Index, SF-36 Short-Form 36, FAOS Foot and Ankle Outcome Score, $n$ volunteer number, $r$ Pearson coefficient correlation

${ }^{*} p<0.05 ; * * 0=0.001$

\section{Reliability}

The means and standard deviations of the total FFI scores and subscales for each reproducibility evaluation (test/ retest) are presented in Table 3.
Table 3 Inter and intra-observer reliability of FFI (total score and subscales)

\begin{tabular}{|c|c|c|c|}
\hline \multirow[t]{2}{*}{ Scores $(n=50)$} & \multicolumn{3}{|l|}{ Mean (SD) } \\
\hline & $\begin{array}{l}\text { st interview } \\
\text { (Evaluator A) }\end{array}$ & $\begin{array}{l}\text { 2nd interview } \\
\text { (Evaluator B) }\end{array}$ & $\begin{array}{l}\text { 3rd interviewc } \\
\text { (Evaluator A) }\end{array}$ \\
\hline FFI Total & $20.54(15.17)$ & $20.57(15.01)$ & $20.32(14.91)$ \\
\hline Disability & $12.34(12.91)$ & $11.85(12.67)$ & $11.62(12.33)$ \\
\hline Activity limitation & $18.89(14.22)$ & $18.71(13.85)$ & $19.28(14.43)$ \\
\hline Pain & $30.39(24.94)$ & $30.57(25.12)$ & $30.63(24.50)$ \\
\hline
\end{tabular}

FFI Foot Function Index, $n$ volunteer number, SD standard deviation

ab Inter-observer evaluation; ${ }^{a c}$ Intra-observer evaluation

The reliability of the FFI total score and all the subscales were considered highly satisfactory. For Cronbach's alpha was found $\alpha=0.78$ for the FFI total score and the subscales vary from 0.80 to 0.61 during the first questionnaire administration. The Brazilian-Portuguese version of FFI showed excellent intra and inter-observer reliability, with an ICC 0.99-0.97 (Table 4).

The standard error of measurement (SEM) associated with the total FFI score was 1.32 points for the interobserver and 1.08 points for the intra-observer evaluation. The minimal detectable change (MDC) was 2.42 points ( $90 \%$ confidence interval) over the time interval of the intra-observer evaluation (maximum of one week). The SEM for the FFI domains ranged from 1.08 to 2.16, whereas the MDC ranged from 2.42 to 3.43 (Table 5).

\section{Ceiling and floor effects}

When administered the FFI questionnaire in patients with plantar fasciitis, metatarsalgia and ankle lateral sprain, no volunteer reached the maximum or minimum score of FFI questionnaire, therefore there were no ceiling and floor effects.

\section{Discussion}

From the results of this study, the Brazilian-Portuguese version of the Foot Function Index questionnaire has shown to be a valid and reliable instrument among patients with foot disorders.

For the FFI validation analysis the total FFI score was used because of its greater practicality for clinical application, unlike previous studies that used the scores of each subscale (Budiman-Mak et al. 1991; Martinelli et al. 2014; Naal et al. 2008; Paez-Moguer et al. 2014; PourtierPiotte et al. 2015; Wu et al. 2008). In this way, the present study found that the FFI correlated with two SF-36 subscales: "bodily pain" and "social role functioning". It was found that, if the SF-36 quality-of-life questionnaire by itself for the validation process, as seen in previous validation studies (Budiman-Mak et al. 1991; Martinelli 
Table 4 Inter and intra-observer reliability analysis of FFI questionnaire

\begin{tabular}{llll}
\hline Scores $(\mathbf{n}=\mathbf{5 0})$ & $\begin{array}{l}\text { Alpha de } \\
\text { Cronbach (IC) }\end{array}$ & $\begin{array}{l}\text { Inter-observer } \\
\text { ICC }\end{array}$ & $\begin{array}{l}\text { Intra-observer } \\
\text { ICC }\end{array}$ \\
\hline FFI total & $0.78(0.68-0.86)$ & 0.99 & 0.99 \\
$\begin{array}{l}\text { Disability } \\
\begin{array}{l}\text { Activity limita- } \\
\text { tion }\end{array}\end{array}$ & $0.80(0.71-0.87)$ & 0.98 & 0.97 \\
Pain & $0.66(0.42-0.74)$ & 0.97 & 0.98 \\
\hline
\end{tabular}

FFI Foot Function Index, $n$ volunteer number, $I C$ internal consistency, ICC intraclass coefficient correlation

et al. 2014; Naal et al. 2008; Pourtier-Piotte et al. 2015; Wu et al. 2008), social and emotional issues, unrelated to orthopedic injuries, could interfere in the findings. Thus, there was a need to add a specific evaluation measurement for the ankle and foot, and this was the first study to use the FAOS (Imoto et al. 2009) in the FFI validation process.

Application of a specific questionnaire that evaluates symptoms and functional limits for the foot and ankle (FAOS) in the FFI validity process made it possible to establish correlations for all the subscales ("pain", "function in daily living", "function in sports and recreation" and "quality of life"), except for "symptoms". This result shows the great importance of FFI validity, thus making this questionnaire a valid instrument for application in clinical practice. The lack of correlation with the "symptoms" subscale may have occurred because of the diversified characteristics of the questions from which it is composed.

In evaluating reliability, the Brazilian-Portuguese version of FFI showed excellent reproducibility intraobserver $(\mathrm{ICC}=0.99)$, thus indicating that the version is as reliable as its original version (ICC $=0.87$ ) (BudimanMak et al. 1991). Furthermore, the reliability of the subscales "pain", "activity limitation" and "disability" showed excellent reproducibility, with ICC of 0.99, 0.98 and 0.97, respectively. The original version of the FFI questionnaire showed values of $0.69,0.81$ and 0.84 , respectively.

In addition to assessing intra-observer reliability with a 1 -week interval, inter-observer reliability was assessed in the present study, with at least a 1-h interval after the first evaluation. This was the first study on the FFI to perform inter-observer reliability assessment. From the results, it was found that the Brazilian version was reliable, with excellent reproducibility values with ICC of $0.99,0.99$, 0.97 and 0.98 for "total score", "pain", "activity limitation" and "disability".

The IC evaluated by Cronbach's alpha was considered adequate $(\alpha=0.78)$ for FFI total score and showed values of $0.66,0.61$ and 0.80 for the subscales "pain", "activity
Table 5 Standard error of measurement (SEM) and minimum detectable change (MDC) from the FFI scores

\begin{tabular}{|c|c|c|c|}
\hline \multirow[t]{2}{*}{ Scores $(n=50)$} & \multirow{2}{*}{$\begin{array}{l}\text { Inter-observer }{ }^{a} \\
\text { SEM }\end{array}$} & \multicolumn{2}{|c|}{ Intra-observer ${ }^{b}$} \\
\hline & & SEM & $\operatorname{MDC}(90 \% \mathrm{Cl})$ \\
\hline FFI Total & 1.32 & 1.08 & 2.42 \\
\hline Disability & 1.77 & 2.15 & 3.43 \\
\hline Activity limitation & 2.16 & 1.56 & 2.91 \\
\hline Pain & 2.03 & 1.82 & 3.15 \\
\hline
\end{tabular}

FFI Foot Function Index, $n$ volunteer number, SEM standard error of measurement, $M D C$ minimal detectable change, $\mathrm{Cl}$ confidence interval

a SEM of inter-observer; ${ }^{\text {bSEM }}$ and MDC of intra-observer after maximum interval of two weeks

limitation" and "disability". These finding indicates that the items of the Brazilian version are homogenous, as the original version, which showed alpha values of 0.95 , $0.94,0.73$ and 0.92 for the "FFI total", "pain", "activity limitation" and "disability", respectively (Budiman-Mak et al. 1991).

This was the first study to use the MDC and SEM as reliability measurements in order to analyze the psychometric properties of the FFI. The MDC was 2.42 points (90\% confidence interval) over the time interval of the intra-observer evaluation (maximum of one week) and the SEM relating to the total FFI score was 1.08 points over the intra-observer and 1.32 points over the interobserver evaluation. These values show that the level of agreement to the Brazilian version of FFI was considered excellent, representing $<5 \%$ of the total score of the FFI (0-100) (Wageck et al. 2013). Furthermore, the Brazilian Version of the FFI questionnaire did not show ceiling and floor effects when administered in patients with foot disorders. This finding indicates that, the Brazilian version of FFI points out that there is no limitation to detect the spectrum of relatively mild foot conditions.

We considered as a limitation of the study, the inclusion of patients with different foot disorders. However, after the validity process in individuals with plantar fasciitis, metatarsalgia and lateral ankle sprain, we found an excellent reliability in determining the functionality in different foot disorders. These findings showed that the FFI questionnaire allowing a large number of people to apply it. Another possible limitation was that, we only used the FFI total score data to correlate with SF-36 and FAOS measures. The subscales were not used. However in clinical practice, the use of the total score indicates the real impact of the foot injuries on the functionality (Budiman-Mak et al. 1991).

The Brazilian-Portuguese version of FFI questionnaire was shown to be valid, highly reproducible regarding both inter and intra-observer evaluation and not show ceiling and floor effects in patients with foot disorders. 
It therefore allows healthcare professionals to objectively evaluate patients' health at the beginning, middle and end of their patient's rehabilitation. For future studies, it is recommended that the responsiveness of this questionnaire should be evaluated, in order to determine whether this instrument is capable of detecting clinical changes in patients after a period of time and also, to identify the normative values of the FFI questionnaire in the Brazilian population. These values will contribute to the correct interpretation of the FFI scores according to the age, gender, and anthropometrics data, to allow the understanding of the clinical improvement after treatment in each evaluated group (Schneider and Jurenitsch 2016).

\section{Conclusion}

The Brazilian-Portuguese version of the FFI questionnaire has shown to be a valid and reliable instrument for foot functioning evaluation, and it can be used in scientific and in clinical practice fields.

\section{Authors' contributions}

BM: participated in the sequence alignment and drafted the manuscript, participated in the sequence alignment, design the study and performed the statistical analysis; IS: participated in the data collection; DK: participated in the collection; EB: participated in the design of the study; LY: conceived of the study, participated in its design and coordination and helped to draft the manuscript. All authors read and approved the final manuscript.

\section{Author details}

1 Department of Human Movement Sciences, Federal University of São Paulo, Rua Silva Jardim, 136, Santos, SP CEP 11015-020, Brazil. ${ }^{2}$ U.S. Department of Veterans Affairs, Washington, DC, USA.

\section{Competing interests}

The authors declare that they have no competing interests.

\section{Ethical approval}

All procedures performed in studies involving human participants were in accordance with the ethical standards of the institutional and/or national research committee and with the 1964 Helsinki declaration and its later amendments or comparable ethical standards.

\section{Informed consent}

Informed consent was obtained from all individual participants included in the study.

Received: 12 June 2016 Accepted: 10 October 2016

Published online: 18 October 2016

\section{References}

Andresen EM (2000) Criteria for assessing the tools of disability outcomes research. Arch Phys Med Rehabil 81:S15-S20. doi:10.1053/ apmr.2000.20619

Beaton DE, Bombardier C, Guillemin F, Ferraz MB (2000) Guidelines for the process of cross-cultural adaptation of self-report measures. Spine (Phila Pa 1976) 25:3186-3191. doi:10.1097/00007632-200012150-00014

Bennett PJ, Patterson C, Wearing S, Baglionin T (1998) Development and validation of a questionnaire designed to measure foot-health status. J Am Podiatr Med Assoc 88:419-428. doi:10.7547/87507315-88-9-419

Binkley JM, Stratford PW, Lott SA, Riddle DL (1999) The Lower Extremity Functional Scale (LEFS): scale development, measurement properties, and clinical application: North American Orthopaedic Rehabilitation Research Network. Phys Ther 79:371-383

Budiman-Mak E, Conrad KJ, Roach KE (1991) The Foot Function Index: a measure of foot pain and disability. J Clin Epidemiol 44:561-570. doi:10.1016/0895-4356(91)90220-4

Ciconelli RM, Ferraz MB, Santos W, Meinão I, Quaresma MR (1999) Brazilian-Portuguese version of the SF-36: a reliable and valid quality of life outcome measure. Rev Bras Reumatol 39:143-150 (Portuguese)

Eechaute C, Vaes P, Van Aerschot L, Asman S, Duquet W (2007) The clinimetric qualities of patient-assessed instruments for measuring chronic ankle instability: a systematic review. BMC Musculoskelet Disord 8:6. doi:10.1186/1471-2474-8-6

Espinosa N, Maceira E, Myerson MS (2008) Current concept review: metatarsalgia. Foot Ankle Int 29:871-879. doi:10.3113/FAl.2008.0000X

Gribble PA, Delahunt E, Bleakley CM, Caulfield B, Docherty CL, Fong DT et al (2014) Selection criteria for patients with chronic ankle instability in controlled research: a position statement of the International Ankle Consortium. J Athl Train 49:121-127. doi:10.4085/1062-6050-49.1.14

Hale SA, Hertel J (2005) Reliability and sensitivity of the Foot and Ankle Disability Index in subjects with chronic ankle instability. J Athl Train 40:35-40

Hunt KJ, Hurwit D (2013) Use of patient-reported outcome measures in foot and ankle research. J Bone Joint Surg Am 95:1-9. doi:10.2106/ JBJS.L.01476

Imoto AM, Peccin MS, Rodrigues R, Mizusaki JM (2009) Translation, cultural adaptation and validation of Foot and Ankle Outcome Score (FAOS) questionnaire into Portuguese. Acta Ortop Bras 17:232-235 (Portuguese)

Kirkley A, Griffin S (2003) Development of disease-specific quality of life measurement tools. Arthroscopy 19(10):1121-1128. doi:10.1016/j. arthro.2003.10.028

Leggin BG, Michener LA, Shaffer MA, Brenneman SK, lannotti JP, Williams GR Jr (2006) The Penn shoulder score: reliability and validity. J Orthop Sports Phys Ther 36:138-151. doi:10.2519/jospt.2006.36.3.138

Lopes AD, Ciconelli RM, Carrera EF, Griffin S, Faloppa F, Dos Reis FB (2008) Validity and reliability of the Western Ontario Rotator Cuff Index (WORC) for use in Brazil. Clin J Sport Med 18:266-272. doi:10.1097/ JSM.0b013e31817282f4

Martin RL, Irrgang JJ (2007) A survey of self-reported outcome instruments for the foot and ankle. J Orthop Sports Phys Ther 37:72-84. doi:10.2519/ jospt.2007.2403

Martin RL, Irrgang JJ, Burdett RG, Conti SF, Van Swearingen JM (2005) Evidence of validity for the Foot and Ankle Ability Measure (FAAM). Foot Ankle Int 26:968-983

Martin RL, Davenport TE, Reischl SF, McPoil TG, Matheson JW, Wukich DK et al (2014) Heel pain-plantar fasciitis: revision 2014. J Orthop Sports Phys Ther 44:A1-A33. doi:10.2519/jospt.2014.0303

Martinelli N, Scotto GM, Sartorelli E, Bonifacini C, Bianchi A, Malerba F (2014) Reliability, validity and responsiveness of the Italian version of the Foot Function Index in patients with foot and ankle diseases. Qual Life Res 23:277-284. doi:10.1007/s11136-013-0435-4

Naal FD, Impellizzeri FM, Huber M, Rippstein PF (2008) Cross-cultural adaptation and validation of the Foot Function Index for use in Germanspeaking patients with foot complaints. Foot Ankle Int 29:1222-1228. doi:10.3113/FAl.2008.1222

Paez-Moguer J, Budiman-Mak E, Cuesta-Vargas Al (2014) Cross-cultural adaptation and validation of the Foot Function Index to Spanish. Foot Ankle Surg 20:34-39. doi:10.1016/j.fas.2013.09.005

Pourtier-Piotte C, Pereira B, Soubrier M, Thomas E, Coudeyre E (2015) French validation of the Foot Function Index (FFI). Ann Phys Rehabil Med 58:276-282. doi:10.1016/j.rehab.2015.07.003

Schneider W, Jurenitsch S (2016) Age- and sex-related normative data for the Foot Function Index FFI in a German-speaking cohort. Foot Ankle Int. doi:10.1177/1071100716659747

Shultz S, Olszewski A, Ramsey O, Schmitz M, Wyatt V, Cook C (2013) A systematic review of outcome tools used to measure lower leg conditions. Int J Sports Phys Ther 8:838-848

Sousa VD, Rojjanasrirat W (2011) Translation, adaptation and validation of instruments or scales for use in cross-cultural health care research: a clear and user-friendly guideline. J Eval Clin Pract 17(2):268-274. doi:10.1111/j.1365-2753.2010.01434.x

Terwee CB, Bot SD, de Boer MR, van der Windt DA, Knol DL, Dekker J et al (2007) Quality criteria were proposed for measurement properties of 
health status questionnaires. J Clin Epidemiol 60:34-42. doi:10.1016/j. jclinepi.2006.03.012

Thomas MJ, Roddy E, Zhang W, Menz HB, Hannan MT, Peat GM (2011) The population prevalence of foot and ankle pain in middle and old age: a systematic review. Pain 152:2870-2880. doi:10.1016/j.pain.2011.09.019

van der Leeden M, Steultjens MP, Terwee CB, Rosenbaum D, Turner D, Woodburn J et al (2008) A systematic review of instruments measuring foot function, foot pain, and foot-related disability in patients with rheumatoid arthritis. Arthritis Rheum 59:1257-1269. doi:10.1002/art.24016

Wageck BB, de Noronha M, Lopes AD, da Cunha RA, Takahashi RH, Costa LO (2013) Cross-cultural adaptation and measurement properties of the Brazilian Portuguese Version of the Victorian Institute of Sport
Assessment-Patella (VISA-P) scale. J Orthop Sports Phys Ther 43:163-171. doi:10.2519/jospt.2013.4287

Williams GN, Molloy JM, DeBerardino TM, Arciero RA, Taylor DC (2003) Evaluation of the Sports Ankle Rating System in young, athletic individuals with acute lateral ankle sprains. Foot Ankle Int 24:274-282

Wu SH, Liang HW, Hou WH (2008) Reliability and validity of the Taiwan Chinese version of the Foot Function Index. J Formos Med Assoc 107:111-118. doi:10.1016/S0929-6646(08)60124-2

Yi LC, Staboli IM, Kamonseki DH, Budiman-Mak E, Arie EK (2015) Translation and cross-cultural adaptation of FFI to Brazilian Portuguese version: FFI-Brazil. Rev Bras Reumatol 55:398-405. doi:10.1016/j.rbre.2014.11.005 (Portuguese)

\section{Submit your manuscript to a SpringerOpen ${ }^{\circ}$ journal and benefit from:}

- Convenient online submission

\section{- Rigorous peer review}

- Immediate publication on acceptance

- Open access: articles freely available online

- High visibility within the field

- Retaining the copyright to your article 